\title{
Concept, diagnosis and classification of bisphosphonate-associated osteonecrosis of the jaws. A review of the literature
}

\author{
Carmen Gavaldá ${ }^{1}$, Jose V. Bagan ${ }^{2}$
}

\begin{abstract}
${ }^{1}$ Associate Professor of Oral Medicine. University of Valencia. Primary Care Dentist. Valencian Public Health Service. Valencia (Spain)

${ }^{2}$ Chairman of Oral Medicine. University of Valencia. Head of the Department of Stomatology. Valencia University General Hospital. Valencia (Spain)
\end{abstract}

Correspondence:

Departamento de Medicina Oral

Clínica Odontológica

c/ Gascó Oliag, 1

46010 Valencia, Spain

carmen.gavalda@uv.es

Gavaldá C, Bagan JV. Concept, diagnosis and classification of bisphosphonate-associated osteonecrosis of the jaws. A review of the literature. Med Oral Patol Oral Cir Bucal. 2016 May 1;21 (3):e260-70.

http://www.medicinaoral.com/medoralfree01/v2133/medoralv21i3p260.pdf

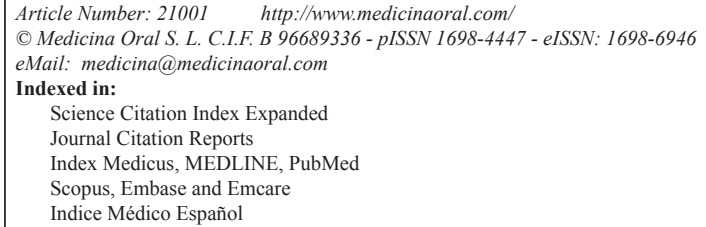

\begin{abstract}
Background: Bisphosphonates (BPs) and other antiresorptive agents such as denosumab are widely prescribed for the treatment of osteoporosis and are also used in patients with multiple myeloma and metastatic breast or prostate cancer for avoiding bone reabsorption and fractures that result in increased morbidity-mortality among such individuals.

Material and Methods: We made a bibliographic search to analyze the concept, diagnosis and the different classifications for bisphosphonate-associated osteonecrosis of the jaws.

Results: Osteonecrosis of the jaws (ONJ) is an important complication of exposure to BPs or other antiresorptive agents, and although its prevalence is low, it can pose management problems. The definition, diagnosis and classification of osteonecrosis have evolved since Marx reported the first cases in 2003.

Conclusions: The present study offers a literature review and update on the existing diagnostic methods and classification of the disorder, with a view to facilitating earlier and more effective treatment.
\end{abstract}

Key words: Osteonecrosis, jaws, bisphosphonates.

\section{Introduction}

Bisphosphonates (BPs) are stable pyrophosphate analogs that modulate bone metabolism, and are generally used to treat certain diseases involving bone reabsorption, such as osteoporosis or Paget's disease (usually administered via the oral route), or hypercalcemia associated to different malignancies such as multiple my- eloma and bone metastases secondary to solid tumors of the breast or other locations (via the intravenous route). Bisphosphonates fundamentally act by inhibiting bone reabsorption, with the limitation of osteoclast acti vity, though they are also considered to exert an antiangiogenic effect $(1,2)$. Other antiresorptive drugs apart from BPs are also used to treat osteoporosis, 
multiple myeloma and bone metastases. In this regard, denosumab (a RANKL inhibitor) has been included in the treatment guides as an option for preventing bone problems (e.g., hip or vertebral fractures), and is administered via the subcutaneous route once every 6 months for the ma-nagement of osteoporosis $(1,3)$. However, the use of both BPs and other antiresorptive drugs can produce adverse effects in the form of gastrointestinal disorders or osteonecrosis of the jaws $(\mathrm{ONJ})$. The latter is defined as an area of exposed or necrotic bone that fails to heal within 8 weeks in patients who have received treatment with BPs in the absence of maxillary radiotherapy (4). The pathogenesis of ONJ remains unclear, though the suppression of osteoclastmediated bone remodeling with consequent bone sclerosis and ischemia has been suggest as the likely causal mechanism. This moreover would explain the increased risk of ONJ when BPs are administered in combination with antiangiogenic agents such as bevacizumab or sunitinib (5).

- Frequency of appearance

BPs for the treatment of osteoporosis

The prevalence of $\mathrm{ONJ}$ is far greater in patients treated with intravenous BPs than in those who receive oral BPs; indeed, some authors consider the association between oral BPs and ONJ to be insignificant (6). As a result, the recommendations regarding dental treatment (e.g., surgery or dental implant placement) in such patients can be vague and lack firm supporting evidence (6).

BPs via the oral route: The prevalence of ONJ varies greatly $(0.001-0.10 \%)$, depending on the literature source $(7,8)$. With a treatment duration of four years or more, the reported prevalence is $0.21 \%$, while the prevalence drops to $0.04 \%$ with shorter treatments (7). In a European multicenter study involving 470 cases of ONJ due to BPs, a total of 37 (7.8\%) were attributed to oral BPs prescribed for the treatment of osteoporosis (6). The clinical significance of the oral route therefore should not be underestimated.

The incidence ranges from 1.04-69 cases per 100,000 patients/year (8). Kühl et al. (9) recorded a mean incidence of $0.12 \%$, while other authors (10) have described incidences of between $0.0009 \%-0.034 \%$.

Intravenous BPs for the treatment of osteoporosis: The ONJ prevalence in this case is greater, between $0-0.348 \%(8)$. The incidence ranges from $0-90$ cases per 100,000 patients/year (8).

Intravenous BPs in cancer treatments

The prevalence of ONJ in cancer patients treated with intravenous BPs varies between 0.52-7.4\%, depending on the source $(3,5,11)$. The incidence in turn ranges from $0.8-12 \%(9,10)$.

On comparing denosumab with BPs in cancer patients, the former drug has been found to offer a greater decrease in bone events and superior safety in patients with kidney disease. However, the associated ONJ rate is similar to that observed with BPs, and hypocalcemia is comparatively more frequent $(12,13)$.

The systemic risk factors for ONJ are the type of BP used, the administration route, the duration of treatment, the cumulative dose, the background disease for which the medication is prescribed, concomitant therapies (e.g., chemotherapy, corticosteroids, antiangiogenic agents, etc.), patient habits (smoking, alcohol, etc.), gender, age, genetic factors, and other disease conditions such as diabetes mellitus, rheumatoid arthritis, hemodialysis, etc. $(5,14)$.

The local risk factors in turn include dentoalveolar surgery (especially extractions) - this being the leading risk factor for ONJ in cancer patients subjected to antiresorptive treatment - as well as dental and periodontal infection, and removable dentures. Anatomical factors (mandible, torus) also play a role $(5,11,14)$.

The aim of this study is to offer an update on the concept, diagnosis and classification of ONJ due to BPs.

\section{Material and Methods}

A literature search was made of the Medline-PubMed, Scopus and Cochrane databases, using the following key words: osteonecrosis, concept, diagnosis, classification, bisphosphonates, staging, jaws. The key words were validated in the MeSH and were combined using the boolean operators AND / OR.

The inclusion criteria were: articles published in English or Spanish in the period between 2006-2015, human studies and reviews, systematic reviews, metaanalyses and consensus documents. In addition, a manual search was made of the references cited in key articles, including relevant letters to the editor and case series. Articles centered on the etiopathogenesis and/or treatment of ONJ were not included.

A total of 675 articles were identified. Of these, 583 were excluded due to duplication and/or after evaluation of the title and abstract. A full-text evaluation was made of the remaining 92 articles, with the final exclusion of 66 publications that were not considered to be sufficiently related to the aspects of $\mathrm{ONJ}$ which we aimed to analyze (Fig. 1).

\section{Results}

Of the 26 articles selected for the present review, most were published in the year $2009(\mathrm{n}=8,30.8 \%)$. The authors were from the United States or Canada in 13 cases $(50 \%)$, and from Europe (Spain, Italy, Denmark, United Kingdom) in 11 cases (42.3\%). One publication was from Japan and one was an international consensus document (United States, Canada, Germany, New Zealand, Japan, Italy, United Kingdom, Jordan, Austria, Denmark, Finland, Switzerland and Saudi Arabia). Ten articles addressed all three aspects reviewed in our 


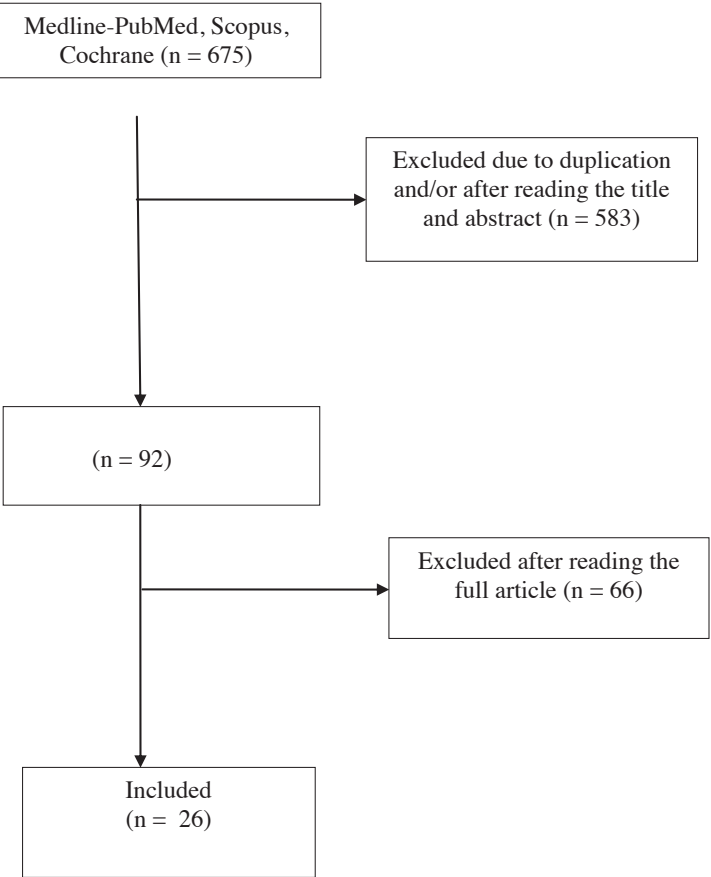

Fig. 1. Article flowchart.

study (concept, diagnosis and treatment) (38.5\%), while the rest addressed one or more of them. Of the total articles selected, 8 were consensus documents, four were letters to the editor, four were case series, one was a case-control study, 5 were reviews, two were clinical cases, and two were retrospective studies (Table 1).

\section{Discussion}

- Concept and diagnosis

A number of terms have been used in reference to osteonecrosis of the jaws due to bisphosphonate exposure, including bisphosphonate-associated osteonecrosis of the jaws (BAONJ), bisphosphonate-related osteonecrosis of the jaws (BRONJ), bisphosphonate-induced osteonecrosis of the jaws (BIONJ), bisphosphonate-related osteonecrosis (BRON), or simply bisphosphonate osteonecrosis (BON) (15).

The first cases of ONJ due to BPs were published by Marx in 2003 (16), and since then there has been a growing number of articles on this subject (17). Since the year 2006 different societies and expert panels have proposed a number of clinical descriptions for defining this new disease entity (18). As an example, in 2006 the American Dental Association (ADA) considered the typical clinical presentation of ONJ to include pain, swelling of the soft tissues, infection, tooth mobility, suppuration and bone exposure. Likewise in 2006, the Australia and New Zealand ONJ work group (19) underscored the lack of a clear definition of the disease. The authors suggested the definition of ONJ as an "area of exposed bone persisting for over 6 weeks". The condition was to be suspected in patients with bone exposure in the maxillofacial region following oral surgery. Other symptoms such as pain and infection could also be present.

In 2006 the American College of Rheumatology (ACR) reported that ONJ typically manifests as an intraoral lesion with the exposure of white-yellowish bone, sometimes associated to the presence of an intra- or extraoral fistula. Likewise in 2006, the American Association of Endodontists (AAE) indicated that patients with ONJ present at least one of the following characteristics: ulceration of the mucosa with bone exposure in the upper maxilla or mandible, pain or swelling, infection and suppuration or sensory alterations (18). It is thus clear that no agreement has been reached regarding the definition of the disease. In the year 2007 the American Association of Oral and Maxillofacial Surgeons (AAOMS), in its position document on BRONJ, defined the latter as the exposure of necrotic bone in the maxillofacial region persisting for more than 8 weeks, in patients with current or past bisphosphonate therapy and no antecedents of radiotherapy of the maxillary region (20). That same year, the American Society for Bone and Mineral Research (ASBMR) defined a "confirmed case" of BRONJ as the presence of an area of exposed bone in the maxillofacial region failing to heal within 8 weeks after having been identified by a health professional in a patient with current or past treatment with BPs and no antecedents of radiotherapy of the maxillary region. A "suspected case" in turn was defined as an area of exposed bone in the maxillofacial region, present for less than 8 weeks, and identified by a health professional in a patient with the same characteristics as described above (21).

In 2008 the Canadian Association of Oral and Maxillofacial Surgeons published a consensus document with management guidelines referred to BRONJ in which the "confirmed case" and "suspected case" definitions introduced by the ASBMR were maintained (22). In 2009 this same work group published a review on the subject in which the same definitions were maintained without changes (23).

The AAOMS, likewise in 2009, published an update on the subject without modifying the definition which they had proposed two years earlier, and which has been maintained up until 2014 (4). However, the AAOMS did introduce a new stage (referred to as stage 0 ), corresponding to patients with symptoms but no exposed bone. Authors such as Colella et al. in 2009 and Bedogni et al. in 2012, among others, considered that the term BRONJ should be redefined in order to include patients in stage $0(24,25)$. Based on clinical cases published by other authors and on the habitual clinical findings, they suggested that the definition of BRONJ should include 
Table 1. Articles selected for the review and their characteristics.

\begin{tabular}{|c|c|c|c|c|c|c|c|}
\hline Authors & Year & Country & & Study vari & ables & Type of sample & Type of article \\
\hline & & & Concept & Diagnosis & Classification & & \\
\hline Ruggiero SL, et al. (31) & 2006 & USA & No & Yes & Yes & $\begin{array}{l}\text { Clinical experience } \\
\text { with } 141 \text { patients and } \\
\text { published articles }\end{array}$ & Review \\
\hline \begin{tabular}{|l|} 
Advisory Task Force on \\
BROJ (AAOMS) (20) \\
\end{tabular} & 2007 & USA & Yes & Yes & Yes & Clinical experience & $\begin{array}{l}\text { Consensus document } \\
\text { Review }\end{array}$ \\
\hline Khosla S, et al. (21) & 2007 & USA & Yes & Yes & Yes & Published articles & $\begin{array}{l}\text { Consensus document } \\
\text { Review }\end{array}$ \\
\hline Bianchi SD, et al. (33) & 2007 & Italy & No & No & Yes & $\begin{array}{l}\text { CT study in } 42 \\
\text { patients }\end{array}$ & Case series \\
\hline McMahon RE, et al. (39) & 2007 & USA & No & Yes & Yes & Clinical experience & Letter to the editor \\
\hline Khan AA, et al. (22) & 2008 & Canada & Yes & Yes & Yes & Published articles & $\begin{array}{l}\text { Consensus document } \\
\text { Systematic review }\end{array}$ \\
\hline Junquera L, et al. (26) & 2008 & Spain & Yes & No & No & $\begin{array}{l}2 \text { cases without bone } \\
\text { exposure }\end{array}$ & Clinical cases \\
\hline Silverman SL, et al. (18) & 2009 & USA & Yes & Yes & Yes & Published articles & Review \\
\hline Khan AA, et al. (23) & 2009 & Canada & Yes & Yes & No & Published articles & $\begin{array}{l}\text { Consensus document } \\
\text { Systematic review }\end{array}$ \\
\hline Ruggiero SL, et al. (4) & 2009 & USA & Yes & Yes & Yes & Published articles & Consensus document \\
\hline Arce K, et al. (35) & 2009 & USA & No & Yes & No & Published articles & Review \\
\hline Morag Y, et al. (36) & 2009 & USA & No & Yes & No & Published articles & Review \\
\hline Mawardi $\mathrm{H}$, et al. (27) & 2009 & USA & Yes & Yes & Yes & $\begin{array}{l}5 \text { cases without bone } \\
\text { exposure }\end{array}$ & Clinical cases \\
\hline Bagán JV, et al. (17) & 2009 & Spain & No & No & Yes & Clinical experience & Letter to the editor \\
\hline Colella G, et al. (24) & 2009 & Italy & Yes & No & No & $\begin{array}{l}\text { Clinical experience } \\
\text { and published articles }\end{array}$ & Letter to the editor \\
\hline Fedele S, et al. (30) & 2010 & UK & No & Yes & No & Study of 332 patients & $\begin{array}{l}\text { Case series } \\
\text { Observational study }\end{array}$ \\
\hline Yoneda T, et al. (40) & 2010 & Japan & No & Yes & Yes & Published articles & $\begin{array}{l}\text { Consensus document } \\
\text { Systematic review }\end{array}$ \\
\hline Patel S, et al. (10) & 2012 & USA & Yes & Yes & Yes & Published articles & Review \\
\hline Bagán JV, et al. (41) & 2012 & Spain & No & No & Yes & Study of 126 patients & Case series \\
\hline Bedogni A, et al. (25) & 2012 & Italy & Yes & Yes & Yes & $\begin{array}{l}\text { Clinical experience } \\
\text { and Published articles }\end{array}$ & Letter to the editor \\
\hline Ruggiero SL, et al. (14) & 2014 & USA & Yes & Yes & Yes & Published articles & $\begin{array}{l}\text { Consensus document } \\
\text { Systematic review }\end{array}$ \\
\hline Schiodt M, et al. (32) & 2014 & Denmark & No & No & Yes & Study of 102 patients & Case series \\
\hline Bedogni A, et al. (34) & 2014 & $\begin{array}{l}\text { Italy and } \\
\text { UK }\end{array}$ & No & Yes & Yes & Study of 799 patients & $\begin{array}{l}\text { Retrospective } \\
\text { multicenter study }\end{array}$ \\
\hline Franco S, et al. (42) & 2014 & Italy & No & No & Yes & Study of 203 patients & Retrospective study \\
\hline Bagán JV, et al. (37) & 2015 & Spain & No & No & Yes & $\begin{array}{l}\text { Study of } 43 \text { cases. } \\
\text { Clinical-CT } \\
\text { correlation }\end{array}$ & Case-control study \\
\hline Khan AA, et al. (8) & 2015 & International & Yes & Yes & Yes & Published articles & $\begin{array}{l}\text { Consensus document } \\
\text { Systematic review }\end{array}$ \\
\hline
\end{tabular}

not only cases with exposed bone but also those with necrotic bone in which bone exposure has not yet occurred (24). Furthermore, they considered that the diagnosis and classification should be based not only on the clinical picture but also on the radiological findings $(24,25)$.

Other investigators such as Bagán et al. in 2009, Junquera and Gallego in 2008, and Mawardi et al. in 2009 $(17,26,27)$, also suggested that ONJ may manifest in the absence of bone exposure, particularly in the early stages, with fistulas, pain and radiographic alterations.
On the other hand, cases have since been published in which ONJ has been associated to other antiresorptive agents such as denosumab or cancer drugs with antiangiogenic effects such as sunitinib, sorafenib, bevacizum$\mathrm{ab}$ or sirolimus. As a result, some authors have proposed other terms such as drug-induced osteonecrosis of the jaws or osteonecrosis of the jaws associated to antiresorptive agents, in reference to this disorder $(10,15)$.

In 2014, the AAOMS proposed a change in nomenclature in favor of the term medication-related osteonecrosis of the jaws (MRONJ) (14). 
In addition to incorporating this change in name of the disease, the AAOMS update of 2014 modified its definition. In this regard, a patient is considered to have MRONJ if all of the following conditions are met (14):

- Current or past treatment with antiresorptive or antiangiogenic drugs.

- Exposed bone or intra- or extraoral fistulization in the maxillofacial region communicating with the bone and persisting for more than 8 weeks.

- No history of maxillary radiotherapy or clear maxillary metastatic disease.

However, in 2015 the International Task Force on Osteonecrosis of the Jaw defined ONJ as follows (8):

- Exposed bone in the maxillofacial region that fails to heal in 8 weeks after identification by a health professional.

- Exposure to an antiresorptive agent.

- No history of craniofacial radiotherapy.

The diagnosis is essentially clinical (28). On the other hand, it must be taken into account that there may be one or more sites of bone exposure (29). Furthermore, these sites may remain asymptomatic for prolonged periods of time (weeks, months or even years), or clinical signs and symptoms may manifest before clinically detectable ONJ develops. Such signs and symptoms consist of pain, bone and/or gingival swelling, erythema, suppuration, soft tissue ulceration, intra- or extraoral fistular trajectories, tooth mobility, paresthesia and even anesthesia, in the absence of any apparent dental/ periodontal cause.

The radiographic findings range from variable radiotransparency or radioopacity to the absence of radiological signs. In the absence of bone exposure, these findings alone were not regarded as sufficient to diagnose BRONJ (21).

At present, the latest update of the AAOMS corresponding to 2014 (14) considers that the presence of these manifestations, even in the absence of bone exposure (equivalent to stage 0 of the 2009 classification) is indicative of prodromal BRONJ, and that over time up to $50 \%$ of these patients will progress towards disease stages 1,2 or 3 .

Clinically, the exposure of necrotic bone mostly occurs after dentoalveolar surgery (extractions or the placement of dental implants), though it can also be spontaneous. The most frequent location is the mandible (62-82\% of the cases), maxilla (8-18\%), or both (up to $20 \%$ of the cases), with a predominance of the molar and premolar regions. The exposed bone is generally colonized by oral bacteria, giving rise to secondary infections $(11,28)$.

The differential diagnosis of ONJ must be made with other conditions such as alveolar osteitis, sinusitis, osteomyelitis, periodontitis/gingivitis, periapical disease caused by caries, mucositis, osteoradionecrosis, tempo- romandibular joint disease and certain forms of cementbone dysplasia with secondary sequestration phenomena $(8,21)$. Accordingly, the patient case history and the clinical examination remain the most sensitive tools for diagnosing $\mathrm{ONJ}(8,30)$.

The two most controversial aspects in the diagnosis of ONJ since the publication of the first case series have been: 1) the diagnosis of ONJ in the absence of bone exposure; and 2) the need for radiological or imaging confirmation of the diagnosis. These two aspects will be examined in greater detail below.

- Diagnosis of ONJ in the absence of exposed bone:

Most authors have accepted the definition of ONJ proposed by the AAOMS in 2007, i.e., an area of exposed bone in the maxillofacial region that fails to heal within 6-8 weeks, in a patient with current or past treatment with BPs but without head and neck radiotherapy. However, as has been commented above, some investigators have suggested that ONJ may manifest without bone exposure, particularly in the early stages of the disease. As an example, in 2008 Junquera and Gallego (26) described two patients with bone sequestration that could be clinically and radiographically classified as corresponding to stage $3 \mathrm{ONJ}$, but without bone exposure. In these cases pain and swelling were the main symptoms. The authors suggested that there is a variant of ONJ without bone exposure. Based on their clinical experience, Bagán et al. in 2009 (17) proposed that the three stages of the 2006 classification of Ruggiero (31) should include patients with intraoral fistulas but no bone exposure, since these patients otherwise could not be assigned to any stage.

In 2009, Mawardi et al. (27) described 5 patients subjected to treatment with BPs who developed deep periodontal pockets, tooth mobility or intraoral fistulas with or without suppuration, with swelling in some cases, and with radiographic alterations (sequestration, sclerosis, lack of post-extraction socket healing), but without exposure of necrotic bone. After several months bone exposure occurred in the same zone. The authors regarded these cases as corresponding to early stage BAONJ and proposed modifying the definition of BONJ to include a new category: "suspected BONJ" or stage 0 s, since in the same way as Bagán et al. (17), they were unable to assign the patients to any of the three established ONJ stages.

On the other hand, Fedele et al. in 2010 (30) studied 332 patients with ONJ and found up to $28.9 \%$ of the subjects to have clinical manifestations consistent with the purported ONJ variant without bone exposure. The clinical manifestations in decreasing order of frequency were maxillary pain, fistulization, bone expansion and gingival swelling. In addition, the symptoms developed spontaneously without previous extractions or surgery, and in $29.1 \%$ of the cases no radiological alterations were observed in the panoramic X-ray or computed to- 
mography explorations. Manifest bone exposure was seen over time (up to two years of follow-up) in 53.1\% of these patients. According to the authors, these findings may have a significant impact upon the existing epidemiological data and on the design of future studies.

According to Patel et al. (10), the absence of exposed bone in patients with ONJ can produce a delay in diagnosis, prolong the disease and cause it to become refractory to treatment. They proposed a diagnostic and therapeutic approach to cases of ONJ without bone exposure based on the symptoms, assessment of the risk factors, the radiographic evidence, and patient refractoriness to medical treatment. The authors suggested a modification of the AAOMS staging or classification system, as will be seen below. In 2014, Schiodt et al. (32) indicated that the proportion of ONJ without bone exposure may be high (29-45\% of all cases of ONJ), and that this fact could result in potential under reporting of the disease in epidemiological studies. The authors evaluated 102 patients with ONJ, with and without bone exposure, and established comparisons between the two groups in order to determine whether they corresponded to the same disease condition or not. No significant differences were found between the two groups in terms of the demographic data, symptoms, clinical and radiological characteristics, histopathological findings or survival. As a result, they concluded that both presentations form part of the same disease and proposed a new ONJ classification including patients without bone exposure, as will be commented below.

Lastly, as we have seen, the AAOMS update of the year 2014 (14) modifies the definition of ONJ, with the inclusion of cases of ONJ without bone exposure, though the classification does not contemplate such presentations.

- Need for radiological or imaging confirmation of the diagnosis:

In 2006, Ruggiero et al. (31), in an article presenting guidelines for the diagnosis, staging and treatment of ONJ, described the existence of both early and late radiographic maxillary changes that could simulate other disorders (periapical disease, osteomyelitis, myeloma or metastatic disease). In the case of important bone involvement, regions with a mottled appearance (similar to the pattern seen in osteomyelitis) could be found. Likewise, widening of the periodontal ligament and bone osteosclerosis could be observed, particularly in the region of the hard lamina. However, according to these authors, the radiographic changes were not evident until important bone alteration had developed. They consequently suggested that the panoramic and periapical X-ray studies might not reveal significant changes in the early stages of ONJ. According to Khosla et al. (21), in the presence of well established disease, imaging techniques are not needed for diagnostic purposes since the presence of exposed bone and other clinical signs and symptoms suffice to identify ONJ. Nevertheless, they recognized that such techniques may be of importance in the early identification of ONJ.

Other authors have used imaging techniques in patients of this kind, including computed tomography (CT), magnetic resonance imaging (MRI), scintigraphy and panoramic and periapical X-rays. As an example, Bianchi et al. in 2007 (33) studied 32 patients with ONJ, comparing the alterations found in panoramic X-rays versus CT. The latter technique was found to be far superior, with the detection of lesions in almost twice as many patients. In all cases CT detected structural alterations of the trabecular bone and cortical erosion. In comparison, the panoramic X-rays failed to detect bone sequestration in almost half of the cases. Intense periosteal reaction was a common finding, and oroantral communications could also be observed. In 2012, Bedogni et al. (25) proposed a new classification of ONJ, as will be seen below, based particularly on the CT findings. Likewise, in 2014 Bedogni et al. (34) conducted a large retrospective multicenter study of the CT findings in 799 patients with ONJ. They found that the severity (extension) of the lesions can be identified and measured with CT much more accurately than with panoramic X-rays or clinical inspection, as proposed by some classifications - including that of the AAOMS of 2009. The authors attempted to correlate the findings with the stages proposed by the AAOMS in 2009, and concluded that these stages are unable to correctly identify disease extent or involvement, except in stage 3 .

On the other hand, in 2009 Arce et al. (35) conducted a review of the findings in ONJ with different imaging techniques. According to these authors, the radiographic findings are not specific. Intraoral and panoramic X-rays may show widening of the lamina dura and of the periodontal ligament, osteolysis, diffuse sclerosis and a lack of post-extraction socket healing. The more advanced the disease the greater the sclerosis and widening of the mandibular canal. Zones of ONJ can be identified in quadrants without exposed bone. Computed tomography offers a three-dimensional view of the extent of the lesion and can detect minor sequestrations. Focal sclerosis with a disorganized trabecular pattern is present in the early stages of the disease, and neck adenopathies and masticatory muscle thickening simulating a tumor mass can be detected. Magnetic resonance imaging in turn can detect bone marrow and soft tissue involvement, nerve bundles and adenopathies. Bone scintigraphy with technetium-99 shows enhanced radionuclide uptake between 10-14 days before bone mineral loss becomes significant enough to be detectable on X-rays. The problem with scintigraphy is its lack of specificity and low resolution (35,36). In 2015, Bagán et al. (37) analyzed the degree of sclerosis in different ONJ stages using CT, and investigated the relationship between the 
degree of sclerosis, the clinical symptoms and the extent of the radiotransparencies in 43 cases - establishing comparisons with a group of 40 controls without bone lesions. The patients with ONJ had more intense sclerosis than the controls $(p<0.01)$. Furthermore, the degree of sclerosis increased with the clinical stage of ONJ and was correlated to the extent of the radiotransparency. Morphological analysis of the necrotic bone (sequestrations) using micro-CT has been unable to demonstrate the existence of unique distinguishing features in patients with ONJ in different stages (38).

- Classification

In 2006, Ruggiero et al. proposed an ONJ classification comprising three stages (31): stage $1=$ bone exposure but without signs or symptoms of infection; stage $2=$ bone exposure/necrosis with clinical evidence of infection; stage $3=$ the above manifestations and also alterations such as pathological fractures, extraoral fistulas or osteolysis extending to the inferior mandibular margin. In 2007 the AAOMS adopted this classification (20), though in addition to the group of patients with BRONJ (with its three stages), it included another group of patients comprising individuals at risk. These patients were defined as subjects without evident exposed or necrotic bone or symptoms, but who have been treated with oral or intravenous BPs.

In the year 2009, the AAOMS added a stage 0 to its classification, involving alterations (pain, tooth mobility, fistulas, radiographic changes, etc.) that may have been due to treatment with BPs, but without exposed bone. The risk of progression towards more advanced stages of the disease was not known at that time (4).

Other classifications have also introduced the idea that ONJ may be present despite the absence of bone exposure. As an example, McMahon et al. considered that an early stage of ONJ with or without symptoms may exist in which bone exposure has not yet occurred, since the first bone changes are found at marrow level, not in cortical bone, and that early detection of this stage could improve the patient prognosis and treatment (39). They also considered that imaging techniques and histological studies are needed to more precisely categorize the different ONJ stages. The authors proposed 6 stages (Table 2), but also considered that a stage 0 could be useful for identifying patients at risk. Mawardi et al. suggested the inclusion of a stage $0 \mathrm{~s}$ as corresponding to "suspected BRONJ". This stage in turn would comprise two subcategories: 0ss in the presence of symptoms, and 0sa in the absence of symptoms (27). Bagán et al. in turn included fistular lesions in stages 1, 2 and 3 , though without bone exposure, and subdivided stage 2 into stages $2 \mathrm{a}$ and $2 \mathrm{~b}$ according to whether the condition responded to conservative management or not (17). Yoneda et al. accepted the definition of ONJ of the AAOMS, but proposed the introduction of four stages in accordance with the situation of the disease in Japan at that time (40). This classification is basically the same as that of the AAOMS of 2009, but stage 0 moreover includes hypoesthesia or anesthesia of the lower lip as symptom and the presence of deep periodontal pockets as clinical sign (Table 2). Other authors such as Bagán et al. in 2012 aimed to validate the classification of the AAOMS of 2009 with a retrospective study of 126 cases of ONJ due to intravenous and oral BPs, comparing both groups and determining whether all the cases could be assigned to one or other of the proposed stages (41). More cases of ONJ without exposed bone were observed in the oral bisphosphonate group, with a larger number of advanced cases (stages 2 or 3 ) in the intravenous oral bisphosphonate group. In addition, 6 cases could not be assigned to any of the stages, for despite the presence of extraoral fistulas and mandibular fracture, no exposed bone was identified. The authors consequently proposed a new modification of the classification of Ruggiero et al. (4), with the inclusion in stage 3 of the term "exposed and necrotic bone or oral fistula without exposed bone" (Table 2). Other classification proposals are described below:

- Bedogni et al. in 2012 proposed a new classification with three stages (25): stage $1=$ focal ONJ, stage $2=$ diffuse ONJ, and 3 = complicated ONJ. In addition to clinical findings, this classification includes CT imaging findings and eliminates stage 0 . According to these authors, the clinical manifestations of pain and suppuration should not be used to differentiate between stages, since they only define symptomatic or asymptomatic forms of BRONJ within one same stage. This contributes to avoid patient migration from stage 1 to stage 2 or vice versa (ping-pong effect). These authors fundamentally used the CT findings to classify the patients. The presence of bone sequestration was not regarded as a sign of complex BRONJ (Table 3).

- According to Franco et al. in 2014, most of the existing classifications are useful from the clinical and diagnostic perspective, but none of them offer a surgical orientation for the treating surgeon (42). They proposed a new dimensional staging system, classifying the lesions by size following panoramic X-ray and CT evaluation, with a view to making treatment decisions easier (Table 3).

- In 2012, Patel et al. modified the classification of the AAOMS of 2009 with the purpose of incorporating patients without bone exposure and of guiding treatment (10). They distinguished between patients with and without bone exposure, and in the latter group those individuals without symptoms were classified as corresponding to stage 1 , while those with symptoms were assigned to stages 2 or 3 (Table 4).

- As has been commented, Schiodt et al. in 2014 considered ONJ with and without bone exposure to corre- 
Table 2. Proposals for modification of the ONJ classification of the AAOMS $(4,20)$ by McMahon et al. (39), Bagán et al. (17,41), Mawardi et al. (27) and Yoneda et al. (40).

\begin{tabular}{|c|c|}
\hline McMahon et al. (2007) & Bagán et al. (2009) \\
\hline $\begin{array}{l}\text { Stage 1: } \\
\text { No exposed/necrotic bone } \\
\text { Moderate and intermittent maxillary pain } \\
\text { Normal dental/mucosal and radiographic findings } \\
\text { Scintigraphy, CT and MRI reveal osteoblastic activity but no } \\
\text { evident infection } \\
\text { Stage 2: } \\
\text { No exposed/necrotic bone } \\
\text { Moderate and constant maxillary pain } \\
\text { Normal dental/mucosal findings, but Rx reveal sclerotic changes } \\
\text { and radiotransparencies } \\
\text { Scintigraphy, CT and MRI show alterations } \\
\text { No evidence of infection } \\
\text { Stage 3: } \\
\text { No apparent exposed/necrotic bone } \\
\text { Constant and severe maxillary pain requiring analgesia } \\
\text { Mucosal edema, erythema with severe pain of the bone alveolar } \\
\text { Dental Rx, scintigraphy, CT and MRI show alterations } \\
\text { There may be infection, though not of dental origin } \\
\text { Stage 4: } \\
\text { <2 cm exposed/necrotic bone without cortical fenestration } \\
\text { Important and constant maxillary pain requiring potent analgesia } \\
\text { The mucosa surrounding the exposed bone is red and swollen } \\
\text { Moderate swelling of the surrounding tissues, without clear } \\
\text { evidence of infection } \\
\text { Dental Rx, scintigraphy, CT and MRI show alterations } \\
\text { Dental disease discarded } \\
\text { Stage 5: } \\
>2 \text { cm exposed/necrotic bone with or without cortical fenestration } \\
\text { Constant and severe maxillary pain requiring analgesia } \\
\text { The mucosa surrounding the exposed bone is red and swollen } \\
\text { Mild to moderate swelling of the peripheral tissues with or without } \\
\text { purulent suppuration } \\
\text { Dental Rx, scintigraphy, CT and MRI show alterations } \\
\text { Dental disease discarded } \\
\text { Stage 6: } \\
>4 \text { cm exposed/necrotic bone with cortical fenestration and } \\
\text { infection } \\
\text { Important and constant maxillary pain requiring potent analgesia } \\
\text { Fetidness. Dental Rx, scintigraphy, CT and MRI show alterations } \\
\text { The mucosa surrounding the exposed bone is red and swollen } \\
\text { One or more of the following: pathological fracture, extraoral } \\
\text { fistula, oroantral fistula, osteolysis extending to the inferior } \\
\text { mandibular margin } \\
\text { Dental disease discarded }\end{array}$ & $\begin{array}{l}\text { Stage 1: } \\
\text { Presence of exposed necrotic bone or small oral fistula without } \\
\text { exposure of necrotic bone } \\
\text { Asymptomatic } \\
\text { Stage 2a: } \\
\text { Presence of exposed necrotic bone or small oral fistula without } \\
\text { exposure of necrotic bone } \\
\text { Patient with symptoms controlled by medical treatment } \\
\text { Stage 2b: } \\
\text { Presence of exposed necrotic bone or small oral fistula without } \\
\text { exposure of necrotic bone } \\
\text { Patient with symptoms not controlled by medical treatment } \\
\text { Stage 3: } \\
\text { Pathological fracture, extraoral fistula, osteolysis extending to the } \\
\text { inferior mandibular margin } \\
\text { Bagán et al. (2012) } \\
\text { The same stages as in the } 2009 \text { classification, but also: } \\
\text { Stage 3: Exposed necrotic bone or oral fistula without exposed } \\
\text { bone, in patients with pain, infection and one or more of the } \\
\text { following: radiographic evidence of bone necrosis extending } \\
\text { beyond the bone alveolar, pathological fracture, extraoral fistula, } \\
\text { oroantral oronasal communication, osteolysis extending to the } \\
\text { inferior mandibular margin or sinus floor }\end{array}$ \\
\hline Mawardi et al. (2009) & Yoneda et al. (2010) \\
\hline $\begin{array}{l}\text { Proposed modification the classification of the AAOMS of } 2007 \\
(20) \text {, introducing a news stage called } 0_{\mathrm{s}} \\
\text { Stage 0s: "suspected ONJ" } \\
\text { Absence of exposed bone } \\
\text { Presence of fistulas, severe tooth mobility, deep periodontal } \\
\text { pockets, positive radiographic findings } \\
2 \text { subcategories: } \\
\text { Stage 0ss: "suspected" and symptomatic } \\
\text { Stage 0sa: "suspected" and asymptomatic }\end{array}$ & $\begin{array}{l}\text { Same specifications as the AAOMS in its classification of } 2009 \text { (4), } \\
\text { except: } \\
\text { Stage } 0 \\
\text { Includes hypoesthesia or anesthesia of the lower lip and/or } \\
\text { Deep periodontal pockets }\end{array}$ \\
\hline
\end{tabular}

Rx: X-ray, MRI: magnetic resonance imaging, CT: computed tomography, ONJ: osteonecrosis of the jaws.

spond to one same disease entity (32). Accordingly, they modified the classification of Patel et al. (10), eliminating stage 0 and classifying patients both with and without bone exposure in stages 1,2 or 3 (Table 4 ).

The classification or staging system currently proposed by the AAOMS (14), and which is correlated to therapeutic strategies specific of each stage, is as follows: - At risk: Patients subjected to antiresorptive or antiangiogenic treatment via the oral or intravenous route, and with no symptoms or apparent bone necrosis. 
Table 3. Proposals for the classification of ONJ according to Bedogni et al. (25) and Franco et al. (42).

\begin{tabular}{|c|c|}
\hline Bedogni et al. (2012) & Franco et al. (2014) \\
\hline 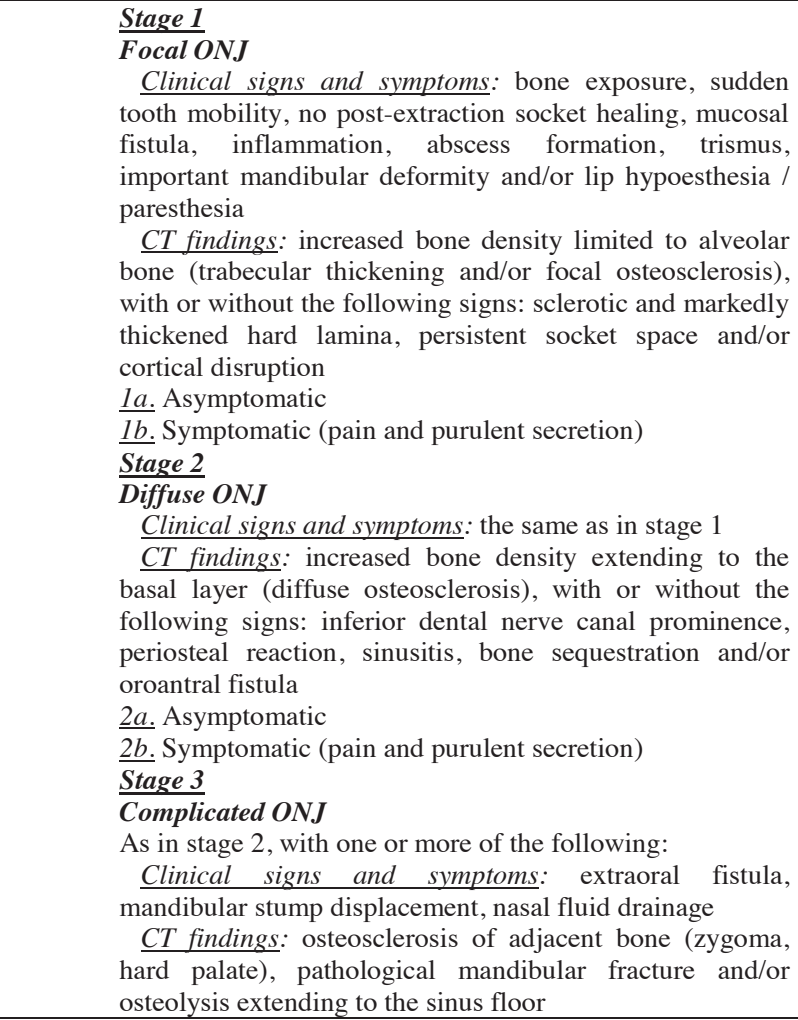 & $\begin{array}{l}\text { Clinical and radiological findings } \\
\text { Stage O } \\
\text { No exposed bone, with nonspecific radiographic } \\
\text { findings such as osteosclerosis and periosteal } \\
\text { hyperplasia, and nonspecific symptoms such as pain } \\
\frac{\text { Stage I }}{\text { Exposed bone and/or radiographic evidence of }} \\
\text { necrotic bone*, or persistent socket space }<2 \mathrm{~cm} \text { in } \\
\text { greater diameter, with or without pain } \\
\frac{\text { Stage II }}{\text { Exposed bone and/or radiographic evidence of }} \\
\text { necrotic bone *, between } 2-4 \mathrm{~cm} \text { in major diameter, with } \\
\text { pain responsive to NSAIDs, and possible abscesses } \\
\text { Stage III } \\
\text { Exposed bone and/or radiographic evidence of } \\
\text { necrotic bone *, }>4 \text { cm in greater diameter, with intense } \\
\text { pain that responds or does not respond to NSAIDs, } \\
\text { abscesses, orocutaneous and/or maxillary sinus } \\
\text { fistulization, with mandibular nerve involvement }\end{array}$ \\
\hline
\end{tabular}

CT: computed tomography, NSAIDs: nonsteroidal antiinflammatory drugs.

* Radiographic evidence of necrotic bone: irregular areas of hypo- and hypercalcification and/or bone sequestration.

Table 4. Proposals for the staging of ONJ according to Patel et al. (10) and Schiodt et al. (32).

\begin{tabular}{|c|c|c|c|}
\hline \multicolumn{2}{|l|}{ Patel et al. (2012) } & \multicolumn{2}{|l|}{ Schiodt et al. (2014) } \\
\hline $\begin{array}{l}\text { Clinical bone } \\
\text { exposure } \\
\text { Same stages as } \\
\text { AAOMS } 2009 \text { (4) }\end{array}$ & $\begin{array}{l}\text { Absence of bone exposure } \\
\text { Asymptomatic } \\
\text { Stage } 1 \mathrm{NE} \\
\text { No clinical evidence of infection; there } \\
\text { may be radiographic findings }{ }^{1} \\
\text { Symptomatic } \\
\text { Stage } 2 \mathrm{NE} \\
\text { No exposed necrotic bone; clinical } \\
\text { evidence of infection, presence of } \\
\text { intraoral fistulas, swelling, pain, } \\
\text { paresthesia / dysesthesia, and } \\
\text { radiographic evidence of bone necrosis } \\
\text { Stage } 3 \mathrm{NE} \\
\text { As in stage } 2 \text { NE, with one or more of } \\
\text { the following: } \\
\text { - Radiographic evidence of bone } \\
\text { necrosis extending beyond alveolar } \\
\text { bone } \\
\text { • Pathological fracture } \\
\text { - Extraoral fistula } \\
\text { - Oroantral, oronasal communication } \\
\text { - Osteolysis extending to the inferior } \\
\text { mandibular margin or sinus floor }\end{array}$ & $\begin{array}{l}\text { Bone exposure } \\
\text { Asymptomatic } \\
\text { Name: } E \text {-ONJ, stage } 1 \\
\text { Bone exposure } \\
\text { Symptoms of infection } \\
\text { Name: } E \text {-ONJ, stage } 2 \\
\\
\text { As in stage } 3 \text { of the AAOMS } \\
\text { Name: } E \text {-ONJ, stage } 3 \\
\end{array}$ & $\begin{array}{l}\text { No bone exposure } \\
\text { Asymptomatic } \\
\text { Name: } N E-O N J, \text { stage } 1 \\
\text { No bone exposure } \\
\text { Symptoms of infection } \\
\text { Name: } N E-O N J, \text { stage } 2 \\
\text { No bone exposure, with } \\
\text { necrosis in patients with pain, } \\
\text { infection, and one or more of } \\
\text { the following: } \\
\text { necrotic bone without exposure, } \\
\text { as evidenced by imaging } \\
\text { techniques, extending beyond } \\
\text { alveolar bone, i.e., inferior } \\
\text { margin or ramus of the } \\
\text { mandible, maxillary sinus and } \\
\text { zygoma, pathological fracture, } \\
\text { extraoral fistula, oroantral or } \\
\text { oronasal communication, } \\
\text { osteolysis extending to the } \\
\text { inferior mandibular margin or } \\
\text { sinus floor } \\
\text { Name: } N E-O N J, \text { stage } 3\end{array}$ \\
\hline
\end{tabular}

1: osteosclerosis, cortical rupture, osteolysis, subperiosteal bone deposit, thickening of the lamina dura, and widening of the periodontal ligament space.

ONJ: osteonecrosis of the jaws; E-ONJ: osteonecrosis of the jaws with exposure; NE-ONJ: osteonecrosis of the jaws with no exposure. 
- Stage 0 (disease variant without bone exposure): No clinical evidence of necrotic bone, though with clinical findings, radiographic changes and nonspecific symptoms.

Among the symptoms:

- Tooth pain in the absence of a dental cause.

- Maxillary bone pain that may irradiate to the region of the temporomandibular joint.

- Pain of the maxillary sinuses that may be associated to inflammation and thickening of the sinus walls.

- Altered neurosensory function.

Among the clinical findings:

- Tooth mobility that cannot be explained by periodontitis.

- Periapical or periodontal fistulas not associated to pulp necrosis secondary to trauma, caries or restorations.

Among the radiographic findings:

- Loss or reabsorption of alveolar bone that cannot be explained by periodontitis.

- Changes in trabecular-dense bone pattern, with no formation of new bone in extraction sockets.

- Zones of osteosclerosis in alveolar bone or around the basal layer.

- Thickening or opacification of the periodontal ligament (thickening of the lamina dura, sclerosis, and reduction of the periodontal ligament space).

- Stage 1: Exposed bone or intra- or extraoral fistulization in the maxillofacial region penetrating to the bone, in asymptomatic patients without evidence of infection. In addition, radiographic findings such as those described in stage 0 may be observed in alveolar bone.

- Stage 2: Exposed bone or intra- or extraoral fistulization in the maxillofacial region penetrating to the bone, with infection evidenced by pain and erythema in the region or exposed bone with suppuration. In addition, radiographic findings such as those described in stage 0 may be observed in alveolar bone.

- Stage 3: Exposed bone or intra- or extraoral fistulization in the maxillofacial region penetrating to the bone, with pain, infection and at least one of the following signs:

- Necrotic bone extending beyond the alveolar bone (inferior margin or ramus of the mandible, maxillary sinus and zygoma)

- Pathological fracture

- Extraoral fistula

- Oroantral or oronasal communication

- Osteolysis extending to the inferior margin of the mandible or sinus floor

As can be seen, no unified classification or staging system has yet been established for use by all professionals - though most studies are based on the classification of the AAOMS. In coincidence with other authors such as Bedogni et al. (25), Patel et al. (10) and Schiodt et al. (32), we consider that stage 0 should be suppressed and that ONJ should be classified into three stages regardless of whether there is bone exposure or not. Furthermore, it would be advisable to establish the diagnosis not only on the basis of the clinical data but also on the findings of the CT scan, since the latter technique offers greater information on the extent and severity of the disorder.

Further studies and consensus are therefore needed with a view to adopting a single international classification allowing the conduction and comparison of epidemiological studies, and contributing to the treatment decision making process.

\section{References}

1. Pichardo SE, van Merkesteyn JP. Bisphosphonate related osteonecrosis of the jaws: spontaneous or dental origin?. Oral Surg Oral Med Oral Pathol Oral Radiol. 2013;116:287-92.

2. Kumar V, Shahi AK. Nitrogen containing bisphosphonates associated osteonecrosis of the jaws: A review for past 10 year literature. Dent Res J (Isfahan). 2014;11:147-53.

3. Qi WX, Tang LN, He AN, Yao Y, Shen Z. Risk of osteonecrosis of the jaw in cancer patients receiving denosumab: a meta-analysis of seven randomized controlled trials. Int J Clin Oncol. 2014;19:40310.

4. Ruggiero SL, Dodson TB, Assael LA, Landesberg R, Marx RE, Mehrotra B, et al. American Association of Oral and Maxillofacial Surgeons position paper on bisphosphonate-related osteonecrosis of the jaw - 2009 update. J Oral Maxillofac Surg. 2009;67:2-12.

5. Campisi G, Fedele S, Fusco V, Pizzo G, Di Fede O, Bedogni A. Epidemiology, clinical manifestations, risk reduction and treatment strategies of jaw osteonecrosis in cancer patients exposed to antiresorptive agents. Future Oncol. 2014;10:257-75.

6. Otto S, Abu-Id MH, Fedele S, Warnke PH, Becker ST, Kolk A, et al. Osteoporosis and bisphosphonates-related osteonecrosis of the jaw: not just a sporadic coincidence-a multi-centre study. J Craniomaxillofac Surg. 2011;39:272-7.

7. Lo JC, O'Ryan FS, Gordon NP, Yang J, Hui RL, Martin D, et al. Prevalence of osteonecrosis of the jaw in patients with oral bisphosphonate exposure. J Oral Maxillofac Surg. 2010;68:243-53.

8. Khan AA, Morrison A, Hanley DA, Felsenberg D, McCauley LK, O'Ryan F, et al. Diagnosis and management of osteonecrosis of the jaw: a systematic review and international consensus. J Bone Miner Res. 2015;30:3-23.

9. Kühl S, Walter C, Acham S, Pfeffer R, Lambrecht JT. Bisphosphonate-related osteonecrosis of the jaws-a review. Oral Oncol. 2012;48:938-47.

10. Patel S, Choyee S, Uyanne J, Nguyen AL, Lee P, Sedghizadeh $\mathrm{PP}$, et al. Non-exposed bisphosphonate-related osteonecrosis of the jaw: a critical assessment of current definition, staging, and treatment guidelines. Oral Dis. 2012;18:625-32.

11. Thumbigere-Math V, Tu L, Huckabay S, Dudek AZ, Lunos S, Basi DL, et al. A retrospective study evaluating frequency and risk factors of osteonecrosis of the jaw in 576 cancer patients receiving intravenous bisphosphonates. Am J Clin Oncol. 2012;35:386-92.

12. Lipton A, Fizazi K, Stopeck AT, Henry DH, Brown JE, Yardley DA, et al. Superiority of denosumab to zoledronic acid for prevention of skeletal-related events: a combined analysis of 3 pivotal, randomised, phase 3 trials. Eur J Cancer. 2012;48:3082-92.

13. Peddi P, Lopez-Olivo MA, Pratt GF, Suarez-Almazor ME. Denosumab in patients with cancer and skeletal metastases: a systematic review and meta-analysis. Cancer Treat Rev. 2013;39:97-104.

14. Ruggiero SL, Dodson TB, Fantasia J, Goodday R, Aghaloo T, Mehrotra B, et al. American Association of Oral and Maxillofacial Surgeons. American Association of Oral and Maxillofacial Surgeons position paper on medication-related osteonecrosis of the jaw-2014 update. J Oral Maxillofac Surg. 2014;72:1938-56. 
15. Ruggiero SL. Emerging concepts in the management and treatment of osteonecrosis of the jaw. Oral Maxillofac Surg Clin North Am. 2013;25:11-20.

16. Marx RE. Pamidronate (Aredia) and zoledronate (Zometa) induced avascular necrosis of the jaws: a growing epidemic. J Oral Maxillofac Surg. 2003;61:1115-7.

17. Bagan JV, Jimenez Y, Diaz JM, Murillo J, Sanchis JM, Poveda R, et al. Osteonecrosis of the jaws in intravenous bisphosphonate use: proposal for a modification of the clinical classification. Oral Oncol. 2009;45:645-6.

18. Silverman SL, Landesberg R. Osteonecrosis of the jaw and the role of bisphosphonates: a critical review. Am J Med. 2009;122(2 Suppl):S33-45.

19. Sambrook P, Olver I, Goss A. Bisphosphonates and osteonecrosis of the jaw. Aust Fam Physician. 2006;35:801-3.

20. American Association of Oral and Maxillofacial Surgeons position paper on bisphosphonate-related osteonecrosis of the jaws. Advisory Task Force on Bisphosphonate-Related Ostenonecrosis of the Jaws, American Association of Oral and Maxillofacial Surgeons. J Oral Maxillofac Surg. 2007;65:369-76.

21. Khosla S, Burr D, Cauley J, Dempster DW, Ebeling PR, Felsenberg D, et al. American Society for Bone and Mineral Research. Bisphosphonate-associated osteonecrosis of the jaw: report of a task force of the American Society for Bone and Mineral Research. J Bone Miner Res. 2007;22:1479-91.

22. Khan AA, Sándor GK, Dore E, Morrison AD, Alsahli M, Amin F, et al. Canadian Association of Oral and Maxillofacial Surgeons. Canadian consensus practice guidelines for bisphosphonate associated osteonecrosis of the jaw. J Rheumatol. 2008;35:1391-7.

23. Khan AA, Sándor GK, Dore E, Morrison AD, Alsahli M, Amin F, et al. Canadian Taskforce on Osteonecrosis of the Jaw. Bisphosphonate associated osteonecrosis of the jaw. J Rheumatol. 2009;36:47890 .

24. Colella G, Campisi G, Fusco V. American Association of Oral and Maxillofacial Surgeons position paper: Bisphosphonate-Related Osteonecrosis of the Jaws-2009 update: the need to refine the BRONJ definition. J Oral Maxillofac Surg. 2009;67:2698-9.

25. Bedogni A, Fusco V, Agrillo A, Campisi G. Learning from experience. Proposal of a refined definition and staging system for bisphosphonate-related osteonecrosis of the jaw (BRONJ). Oral Dis. 2012;18:621-3.

26. Junquera L, Gallego L. Nonexposed bisphosphonate-related osteonecrosis of the jaws: another clinical variant?. J Oral Maxillofac Surg. 2008;66:1516-7.

27. Mawardi H, Treister N, Richardson P, Anderson K, Munshi N, Faiella RA, et al. Sinus tracts - an early sign of bisphosphonateassociated osteonecrosis of the jaws?. J Oral Maxillofac Surg. 2009;67:593-601.

28. Tubiana-Hulin M, Spielmann M, Roux C, Campone M, Zelek L, Gligorov J, et al. Physiopathology and management of osteonecrosis of the jaws related to bisphosphonate therapy for malignant bone lesions. A French expert panel analysis. Crit Rev Oncol Hematol. 2009;71:12-21.

29. Margaix-Muñoz M, Bagan J, Poveda-Roda R. Intravenous bisphosphonate-related osteonecrosis of the jaws: influence of coadjuvant antineoplastic treatment and study of buccodental condition. Med Oral Patol Oral Cir Bucal. 2013;18:e194-200.

30. Fedele S, Porter SR, D’Aiuto F, Aljohani S, Vescovi P, Manfredi M, et al. Nonexposed variant of bisphosphonate-associated osteonecrosis of the jaw: a case series. Am J Med. 2010;123:1060-4.

31. Ruggiero SL, Fantasia J, Carlson E. Bisphosphonate-related osteonecrosis of the jaw: background and guidelines for diagnosis, staging and management. Oral Surg Oral Med Oral Pathol Oral Radiol Endod. 2006;102:433-41.

32. Schiodt M, Reibel J, Oturai P, Kofod T. Comparison of nonexposed and exposed bisphosphonate-induced osteonecrosis of the jaws: a retrospective analysis from the Copenhagen cohort and a proposal for an updated classification system. Oral Surg Oral Med Oral Pathol Oral Radiol. 2014;117:204-13.
33. Bianchi SD, Scoletta M, Cassione FB, Migliaretti G, Mozzati M. Computerized tomographic findings in bisphosphonate-associated osteonecrosis of the jaw in patients with cancer. Oral Surg Oral Med Oral Pathol Oral Radiol Endod. 2007;104:249-58.

34. Bedogni A, Fedele S, Bedogni G, Scoletta M, Favia G, Colella G, et al. Staging of osteonecrosis of the jaw requires computed tomography for accurate definition of the extent of bony disease. Br J Oral Maxillofac Surg. 2014;52:603-8.

35. Arce K, Assael LA, Weissman JL, Markiewicz MR. Imaging findings in bisphosphonate-related osteonecrosis of jaws. J Oral Maxillofac Surg. 2009;67:75-84.

36. Morag Y, Morag-Hezroni M, Jamadar DA, Ward BB, Jacobson JA, Zwetchkenbaum SR, et al. Bisphosphonate-related osteonecrosis of the jaw: a pictorial review. Radiographics. 2009;29:1971-84.

37. Bagan JV, Cibrian RM, Lopez J, Leopoldo-Rodado M, Carbonell E, Bagán L, et al. Sclerosis in bisphosphonate-related osteonecrosis of the jaws and its correlation with the clinical stages: study of 43 cases. Br J Oral Maxillofac Surg. 2015;53:257-62.

38. Allen MR, Pandya B, Ruggiero SL. Lack of correlation between duration of osteonecrosis of the jaw and sequestra tissue morphology: what it tells us about the condition and what it means for future studies. J Oral Maxillofac Surg. 2010;68:2730-4.

39. McMahon RE, Bouquot JE, Glueck CJ, Griep JA, Adams WR, Spolnik KJ, et al. Staging bisphosphonate-related osteonecrosis of the jaw should include early stages of disease. J Oral Maxillofac Surg. 2007;65:1899-900.

40. Yoneda T, Hagino H, Sugimoto T, Ohta H, Takahashi S, Soen S, et al. Bisphosphonate-related osteonecrosis of the jaw: position paper from the Allied Task Force Committee of Japanese Society for Bone and Mineral Research, Japan Osteoporosis Society, Japanese Society of Periodontology, Japanese Society for Oral and Maxillofacial Radiology, and Japanese Society of Oral and Maxillofacial Surgeons. J Bone Miner Metab. 2010;28:365-83.

41. Bagan JV, Hens-Aumente E, Leopoldo-Rodado M, Poveda-Roda R, Bagan L. Bisphosphonate-related osteonecrosis of the jaws: study of the staging system in a series of clinical cases. Oral Oncol. 2012;48:753-7.

42. Franco S, Miccoli S, Limongelli L, Tempesta A, Favia G, Maiorano E, et al. New dimensional staging of bisphosphonate-related osteonecrosis of the jaw allowing a guided surgical treatment protocol: long-term follow-up of 266 lesions in neoplastic and osteoporotic patients from the university of bari. Int J Dent. 2014;2014:935657.

\section{Conflict of interest}

The authors have declared that no conflict of interest exist. 